\title{
Real-time remote detection and measurement for airborne imaging spectroscopy: a case study with methane
}

\author{
D. R. Thompson ${ }^{1}$, I. Leifer ${ }^{2}$, H. Bovensmann ${ }^{3}$, M. Eastwood ${ }^{1}$, M. Fladeland ${ }^{4}$, C. Frankenberg ${ }^{1}$, K. Gerilowski ${ }^{3}$, \\ R. O. Green ${ }^{1}$, S. Kratwurst ${ }^{3}$, T. Krings ${ }^{3}$, B. Luna ${ }^{4}$, and A. K. Thorpe ${ }^{1}$ \\ ${ }^{1}$ Jet Propulsion Laboratory, California Institute of Technology, Pasadena, CA, USA \\ ${ }^{2}$ Bubbleology Research International, Solvang, CA, USA \\ ${ }^{3}$ University of Bremen, Institute of Environmental Physics, P.O. Box 330440, 28334 Bremen, Germany. \\ ${ }^{4}$ NASA Ames Research Center, Moffett Field, CA, USA \\ Correspondence to: D. R. Thompson (david.r.thompson@jpl.nasa.gov)
}

Received: 15 March 2015 - Published in Atmos. Meas. Tech. Discuss.: 22 June 2015

Revised: 10 September 2015 - Accepted: 10 September 2015 - Published: 19 October 2015

\begin{abstract}
Localized anthropogenic sources of atmospheric $\mathrm{CH}_{4}$ are highly uncertain and temporally variable. Airborne remote measurement is an effective method to detect and quantify these emissions. In a campaign context, the science yield can be dramatically increased by real-time retrievals that allow operators to coordinate multiple measurements of the most active areas. This can improve science outcomes for both single- and multiple-platform missions. We describe a case study of the NASA/ESA $\mathrm{CO}_{2}$ and MEthane eXperiment (COMEX) campaign in California during June and August/September 2014. COMEX was a multi-platform campaign to measure $\mathrm{CH}_{4}$ plumes released from anthropogenic sources including oil and gas infrastructure. We discuss principles for real-time spectral signature detection and measurement, and report performance on the NASA Next Generation Airborne Visible Infrared Spectrometer (AVIRISNG). AVIRIS-NG successfully detected $\mathrm{CH}_{4}$ plumes in realtime at $\mathrm{Gb} \mathrm{s}^{-1}$ data rates, characterizing fugitive releases in concert with other in situ and remote instruments. The teams used these real-time $\mathrm{CH}_{4}$ detections to coordinate measurements across multiple platforms, including airborne in situ, airborne non-imaging remote sensing, and groundbased in situ instruments. To our knowledge this is the first reported use of real-time trace-gas signature detection in an airborne science campaign, and presages many future applications. Post-analysis demonstrates matched filter methods providing noise-equivalent $(1 \sigma)$ detection sensitivity for $1.0 \% \mathrm{CH} 4$ column enhancements equal to $141 \mathrm{ppm} \mathrm{m}$.
\end{abstract}

\section{Introduction}

Airborne imaging spectrometers have been deployed for a wide range of scientific, regulatory, and disaster response objectives. Traditionally these campaigns wait for favorable environmental conditions and then fly pre-arranged survey patterns (typically "mowing the lawn"), recording data for post-flight radiometric calibration and geolocation. Significant time can pass before data are analyzed fully, and results often arrive too late for mid-course corrections during the campaign. However, improvements in computing power, communication, and telemetry are changing this situation. Tactical remote measurement generates in-flight calibrated data products to inform a real-time adaptive survey strategy. This can be coordinated to direct other platforms in multiplatform campaigns. We use the term "tactical" to emphasize environmental awareness and real-time decision making, with no military connotation. Its applications include the following.

i. Detection of transient or rare targets - Many airborne missions hunt isolated or nonstationary phenomena. Examples include trace-gas emissions (Aubrey et al., 2015; Gerilowski et al., 2015), algal blooms (Karaska et al., 2004), invasive species (Ustin et al., 2002), isolated microhabitats (Thompson et al., 2013b), and hurricane intensity (Braun et al., 2013). Aircraft use radar to hunt extreme weather, and lidar to find cirrus, thunderstorms or biomass burning (Rolph, 2003). In each case, tactical remote measurement can identify desired 
features (and equally importantly, their absence) during flight, permitting flight plan adjustments to improve coverage (Davis et al., 2010). This reveals features' temporal evolution and improves measurement confidence. During multi-platform campaigns, real-time environmental awareness can guide teams acquiring complementary in situ measurements.

ii. Disaster response - Remote measurements play a critical role in disaster response to oil spills (Leifer et al., 2012; Clark et al., 2010; Reuter et al., 1995), search and rescue (Eismann et al., 2009), fires (Ambrosia et al., 2003, 2011; Mandl et al., 2008; Dennison and Roberts, 2009), and earthquakes (Kruse et al., 2014). In any disaster, information arrives at the incident command center from a range of sources of differing reliability. Remote measurements can contribute repeatable and objective analysis, allowing more efficient, confident allocation of ground and airborne assets while keeping responders safe. The immediate risks to human life demand short response times, for which tactical measurement can provide situational awareness.

iii. Data quality assurance - Tactical remote measurement adds flexibility and confidence to flight management decisions. Currently, mid-campaign flight planning often occurs without knowing the quality of data already collected. This risks wasting resources if, for example, the mission continues under marginal environmental conditions. On the other hand, conservative planning can miss opportunities. Tactical science products can inform flight plans and mid-day scrub decisions to avoid spending flight hours on low-value or redundant data. For example, it may reveal interference such as cirrus clouds (Gao et al., 1993a), sun glint (Kay et al., 2009), and unacceptable aerosol scattering (Bojinski et al., 2002). This also allows instrument subsystem failures to be recognized and addressed immediately.

iv. Robotic exploration - Real-time analysis can improve autonomous operations when communication opportunities are rare and bandwidth is limited, such as in space exploration. Remote spacecraft that are out of touch with ground control can autonomously detect highvalue spectral signatures that guide prioritized downlink or trigger additional measurements (Thompson et al., 2013a). Operators can generate compact map products onboard the spacecraft and downlink them to supplement raw spectra, expanding spatial coverage at a low bandwidth cost. Onboard cloud screening is one example of data volume reduction; it can improve yields by a factor of 2 or more for Earth orbiting instruments (Thompson et al., 2014).

v. Hypothesis formation and testing - Real-time data analysis and visualization in a mapping environment, like
Google Earth (Google Earth, 2015), is common in surface and airborne in situ applications. Many systems allow the scientist to visualize spatial relationships between measured parameters, forming hypotheses on the fly for immediate testing. Adaptive surveying can address new hypotheses during the campaign, while instruments are deployed and environmental conditions are favorable. Telemetering live data allows remote investigators to observe and participate in operational decisions (Leifer et al., 2014).

These techniques require high-performance data telemetry and communication. As the technologies proliferate, unanticipated applications are likely to appear - just as instant results from the digital CCD transformed chemical photography in dramatic and unforeseen ways.

This study demonstrates tactical remote measurement with imaging spectroscopy during a multi-aircraft, multi-platform campaign, $\mathrm{CO}_{2}$ and MEthane eXperiment (COMEX). The COMEX campaign was funded by NASA and ESA to explore synergies between NASA's proposed HyspIRI (Hyperspectral Infrared Imager) mission and ESA's CarbonSat Earth Explorer 8 candidate mission. Greenhouse gas emissions were measured from a range of important anthropogenic sources. Investigators surveyed landfills, husbandry, and fossil-fuel production sites in southern California during summer and fall, 2014. A multi-scale experimental design combined airborne and surface measurements to characterize $\mathrm{CH}_{4}$ sources on scales of meters to tens of kilometers. Ground-validated airborne imaging spectroscopy identified sources and their heterogeneity. This was followed by downwind surface surveys together with airborne sounding and in situ observations transecting plumes at different upwind and downwind distances. Surface mobile survey teams carried sensors to specific locations of interest. Finally, repeated surface in situ surveys studied longer term temporal variability and larger spatial context.

COMEX exploited tactical remote measurements from multiple platforms. We focus on one participating instrument, the Airborne Visible Infrared Spectrometer - Next Generation (AVIRIS-NG) (Hamlin et al., 2011; Green et al., 1998), which mapped $\mathrm{CH}_{4}$ enhancements in real time. A simple detection method based on a band ratio (BR) was sufficient to detect several sources and enhance the COMEX campaign. These initial results motivated the development of a more sophisticated matched filter detection approach, described in this paper, which was developed after COMEX and has been adopted by subsequent $\mathrm{CH}_{4}$ monitoring campaigns. Although prior studies quantified $\mathrm{CH}_{4}$ anomalies using Visible Shortwave Infrared (VSWIR) imaging spectrometers (Roberts et al., 2010; Bradley et al., 2011), we believe the COMEX campaign to be the first real-time tactical deployment for remote trace-gas imaging.

Section 2 describes the real-time algorithms, system architecture, and implementation decisions. Section 3 reviews the 
campaign results including an AVIRIS-NG sensitivity analysis and discussion of lessons learned. We conclude with a discussion of future directions for tactical remote sensing.

\section{Tactical imaging spectroscopy}

The visible/shortwave infrared (VSWIR) imaging spectrometers serve diverse applications including mineralogical mapping (Kruse, 2012), characterization of coastal and terrestrial ecosystems (Ustin et al., 2004), and atmospheric studies (Popp et al., 2012). Imaging spectrometers are valuable for tactical operations because they can map and localize targets over wide areas, providing reconnaissance for other instruments along with spatial and spectral context. Realtime airborne imaging spectroscopy has been deployed in a few previous instances. For example, Thompson et al. (2014) demonstrated real-time cloud screening for future space missions. Bue et al. (2015) calculated reflectance products using the model-based ATREM atmospheric correction. Eismann et al. (2009) demonstrated the ARCHER system which provided real-time processing for search and rescue applications. They performed matched filter spectral signature detection and change detection using the chronochrome method (Schaum and Stocker, 1998). They also demonstrated spectral anomaly detection using the Reed-Xiaoli (RX) detector (Stein et al., 2002), an anomaly score based on the Mahalanobis distance (Chang and Chiang, 2002). These methods detected artificial objects in wilderness scenes, such as parts of aircrafts and vehicles near crash sites. Another real-time airborne investigation used non-imaging spectroscopy for detecting dangerous volcanic plumes (Vogel et al., 2011). On the ground, real-time analysis has imaged these plumes' $\mathrm{SO}_{2}$ and $\mathrm{SiF}_{4}$ absorption (Lübcke et al., 2013; Stremme et al., 2012), enabling subsequent analysis to infer emission rates Krueger et al. (2013).

This section describes the real-time system used by AVIRIS-NG during the COMEX campaign. AVIRIS-NG measures reflected sunlight in the $0.38-2.5 \mu \mathrm{m}$ range with $0.005 \mu \mathrm{m}$ spectral resolution. Its $1 \mathrm{mrad}$ instantaneous field of view (iFOV) provides sub-meter ground sampling distance (GSD). The real-time system characterizes $\mathrm{CH}_{4}$ plumes by analyzing absorption features from 2.1-2.4 $\mu \mathrm{m}$ (Clark et al., 2009). Its design must balance the competing needs of speed and algorithm sensitivity, and several guiding requirements drive our decisions.

First, the system must provide a sensitivity floor sufficient to detect the phenomena of interest reliably. In other words, it must have a signal to noise ratio (SNR) sufficient to find sources under relevant wind, illumination, and substrate conditions. Only then can planners safely act on a null detection result. For similar reasons, it must minimize false positives. Prior studies of $\mathrm{CH}_{4}$ with the "Classic" AVIRIS instrument by Thorpe et al. (2014) detected local enhancements of $1 \mathrm{ppm}$ within a kilometer-thick atmospheric model layer. Later stud- ies by Thorpe et al. (2015) using AVIRIS-NG found similar enhancements in the distal regions of plumes associated with $\mathrm{CH}_{4}$ fluxes of $14.2 \mathrm{~m}^{3} \mathrm{~h}^{-1}$ (500 standard cubic feet per hour, scfh) under moderate $\left(5 \mathrm{~m} \mathrm{~s}^{-1}\right)$ winds. Resolving plumes of this magnitude under similar conditions should be possible with a sensitivity of $1000 \mathrm{ppm} \mathrm{m}$. Better performance would further reduce ambiguity and improve the detail of diffuse plumes.

A second requirement is high spatial resolution. The phenomena should subtend multiple pixels with sufficient resolution for the operator to identify typical morphologies. The diagnostic shape of atmospheric plumes can be corroborated with ancillary wind information (Dennison et al., 2013), while in the case of oil slicks thickness asymmetry and shape are useful cues (Leifer et al., 2012). For plumes, resolution can enhance detection sensitivity due to non-uniformity: many plumes are initially buoyant, rising abruptly in a column for tens of meters before dispersing downwind. High spatial resolution avoids diluting this feature, which may be only a few meters in diameter. Fine spatial resolution also helps exclude false positives caused by artificial features with obvious geometric shapes. For these reasons, we desired that the system would process AVIRIS-NG at native resolution without subsampling.

A third requirement is speed. Speed follows a "threshold" utility function: the system must operate at the instrument data rate, but additional performance provides no extra benefit. Real-time operation avoids a confusing temporal association puzzle where a detection appears at a location passed seconds or minutes ago. In addition, keeping pace with data collection simplifies operations by permitting the system to operate whenever the instrument collects data. We find it possible to implement many of the most common detection methods from literature within this requirement, though speed considerations determine the physical quantities that we retrieve. Specifically, we focus on measuring plume absorption along the optical path. This is sufficient to indicate the relative strengths of different sources. We do not estimate the vertical structure or flux; such products generally require complex iterative retrievals involving ancillary data such as wind speed, and are less critical for real-time decisions.

The real-time system first executes the standard AVIRISNG ground data pipeline to create calibrated radiance measurements. It then matches these spectra to the known gas absorption signature of $\mathrm{CH}_{4}$. The procedure successfully operates at instrument data rates of approximately $500 \mathrm{Mb} \mathrm{s}^{-1}$ and allows operators to detect $\mathrm{CH}_{4}$ emissions in real time. The following sections detail specific design choices for the software architecture and detection algorithms.

\subsection{Instrument and software architecture}

The AVIRIS-NG instrument acquires 598 cross-track spectra at $100 \mathrm{~Hz}$. Frames are captured with a custom field programmable gate array (FPGA) frame grabber over a dedi- 


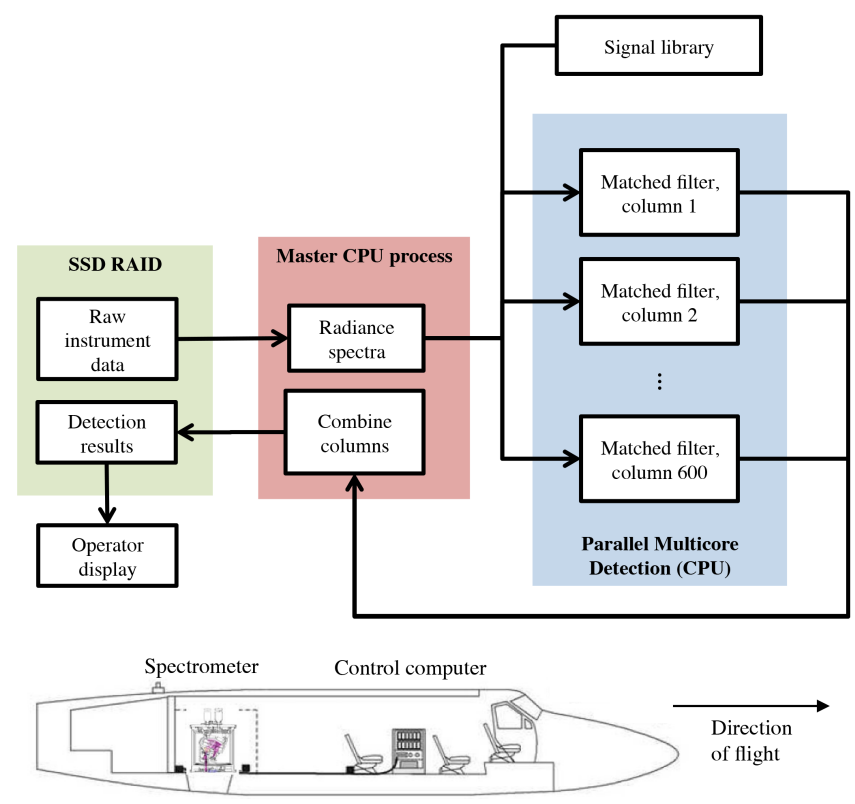

Figure 1. The computing architecture for real-time spectral analysis leverages multi-core parallelism.

cated Camera Link interface at $500 \mathrm{Mbs}^{-1}$ data rate. Data are synchronized with an onboard inertial measurement unit (IMU)/GPS system (Keymeulen et al., 2014), and finally stored in a solid-state RAID array. The AVIRIS-NG console records un-orthorectified raw data and displays it for the operator. A backup computer records a second copy in parallel, and the detection system runs on this machine. Real-time analysis requires that detection algorithms keep pace with the data recording rate, while leaving enough CPU cycles for the backup data recorder.

Our solution exploits parallelism with multi-core CPUs (Fig. 1). A watchdog process waits for a new image to appear on disk. As the instrument writes to this file, an executive real-time process begins reading from the other end and buffering 1000 lines at a time. The real-time analysis applies radiometric calibrations to each 1000-line block and partitions the resulting data into spatially independent regions for multi-thread detection. When all threads have finished, the results are reassembled and recorded to storage, where they are immediately available on the operator display. The system processes $10 \mathrm{~s}$ intervals of data in well under $10 \mathrm{~s}$, achieving the real-time speed requirement.

\subsection{Onboard radiance processing}

The detection pipeline first transforms the frame (a single cross-track slice of data) to a calibrated radiance product (Green, 1998; Hamlin et al., 2011). We calculate radiance in $\mathrm{W} \mathrm{cm}{ }^{-2} \mathrm{~nm}^{-1} \mathrm{sr}^{-1}$ at each cross-track spatial location $c$ and

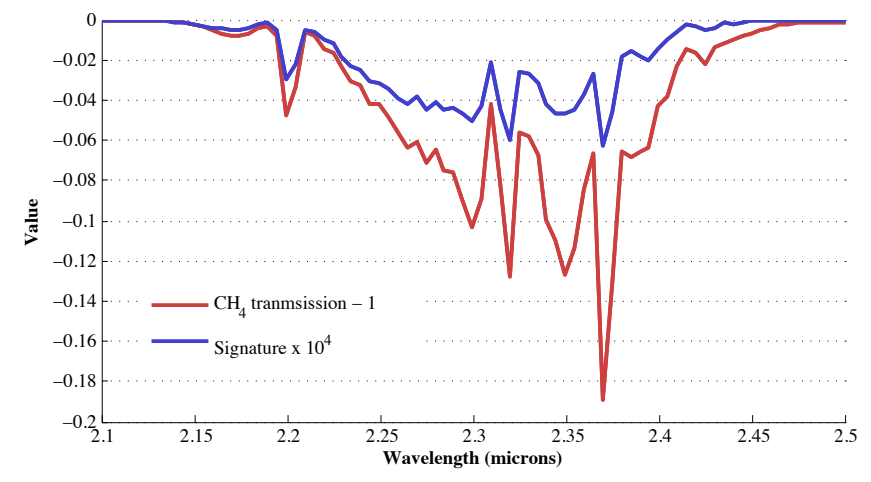

Figure 2. A comparison of spectral shapes between the $\mathrm{CH}_{4}$ transmission spectrum, resampled to AVIRIS-NG wavelengths, and the target signature $t$ used for detection. The vertical axis plots two different quantities as noted in the legend. Both signatures were calculated from a 20-layer atmosphere based on HITRAN 2012 absorption cross sections (Brown et al., 2013).

wavelength $\lambda$ using:

$L_{\mathrm{m}}(c, \lambda)=\left(R(c, \lambda)-R_{\mathrm{d}}(c, \lambda)-R_{\mathrm{p}}(c)\right) \frac{r(\lambda)}{f(c, \lambda)}$,

where $R(c, \lambda)$ are the raw digital numbers from the instrument. $R_{\mathrm{d}}(c, \lambda)$ is the electronic dark current estimated from a closed-shutter segment at the beginning of each flight line. $R_{\mathrm{p}}(c)$ are electronic "pedestal shift" effects, in which a spatially compact signal depresses the signal at other spatial locations. The onboard system estimates the pedestal shift of each spectrum based on the residual dark current in nonilluminated edges of the detector. $r(\lambda)$ and $f(c, \lambda)$ are the radiometric calibration coefficients and flat field corrections, respectively. Both are calculated from laboratory calibration sequences using a known spatially uniform illuminant under fixed imaging geometry. Appendix A discusses wavelength calibration.

\subsection{Onboard signature detection}

Figure 2 shows a typical $\mathrm{CH}_{4}$ transmission signature, calculated using a model atmosphere with absorption coefficients of Brown et al. (2013). The detection algorithm calculates a scalar score to estimate any local enhancement of this background. We evaluated several detection algorithms based on their sensitivity and speed. At one extreme, an iterative nonlinear or "optimal estimation" solution such as iterative maximum a posteriori differential optical absorption spectroscopy (IMAP-DOAS) (Frankenberg et al., 2005; Thorpe et al., 2014) is more quantitative, but somewhat slow for real-time operation. At the other extreme, an absorption band depth score uses simple arithmetic, but its low SNR can detect only the strongest signatures. This paper focuses on a third approach: a novel matched filter variant with a good balance of sensitivity, stability, and speed, and which also permits a quantitative interpretation. 
Our first algorithm uses a continuum interpolated band ratio (CIBR), defined as the depth of an absorption feature relative to a local linear continuum (Green et al., 1989; Bruegge et al., 1990). It is written as follows:

$$
\mathrm{CIBR}=\frac{L_{\mathrm{m}}\left(c, \lambda_{\text {center }}\right)}{w_{\text {left }} L_{\mathrm{m}}\left(c, \lambda_{\text {left }}\right)+w_{\text {right }} L_{\mathrm{m}}\left(c, \lambda_{\text {right }}\right)},
$$

where $\lambda_{\text {center }}, \lambda_{\text {left }}$, and $\lambda_{\text {right }}$ are wavelengths in the middle and either side of the absorption feature. The weighting coefficients $w$ sum to unity, and make the denominator the linearly interpolated continuum at the location of the absorption center $\lambda_{\text {center }}$. We find the $2.37 \mu \mathrm{m}$ feature provides the best overall contrast. The CIBR method is simple to implement and fast to execute. For the sources studied during COMEX, its sensitivity is sufficient to detect strong local $\mathrm{CH}_{4}$ enhancements.

The second detection strategy is a classical matched filter (Manolakis et al., 2014), a variant of which was used previously for $\mathrm{CH}_{4}$ detection by Thorpe et al. (2013). The matched filter tests each spectrum against a target signature $t$ while accounting for the background covariance. Here $t$ is a vector with one element per wavelength. If the background spectra are distributed as a multivariate Gaussian $\mathcal{N}$ with mean vector $\boldsymbol{\mu}$ and covariance matrix $\boldsymbol{\Sigma}$, the matched filter is equivalent to a hypothesis test between the case $H_{0}$ where the target is absent and $H_{1}$ where it is present.

$$
\begin{aligned}
& H_{0}: L_{\mathrm{m}} \sim \mathcal{N}(\boldsymbol{\mu}, \boldsymbol{\Sigma}) \\
& H_{1}: L_{\mathrm{m}} \sim \mathcal{N}(\boldsymbol{\mu}+\boldsymbol{t} \alpha, \boldsymbol{\Sigma})
\end{aligned}
$$

Here, $t$ is the target signature. The matched filter estimates the scalar value $\alpha$, the fraction of the target (potentially larger than unity) which perturbs the background. Larger values of $\alpha$ signify a stronger match. The matched filter is written.

$$
\alpha(x)=\frac{(\boldsymbol{t}-\hat{\boldsymbol{\mu}})^{T} \hat{\boldsymbol{\Sigma}}^{-1}(x-\hat{\boldsymbol{\mu}})}{\sqrt{(\boldsymbol{t}-\hat{\boldsymbol{\mu}})^{T} \hat{\boldsymbol{\Sigma}}^{-1}(\boldsymbol{t}-\hat{\boldsymbol{\mu}})}}
$$

The hat symbols indicate that the background mean vector and covariance matrix are estimated using samples from the scene. One typically draws samples from a rectangular region near the target. However, most push-broom sensors have a slightly nonuniform behavior at different cross-track positions, which violates the Gaussian background assumption. The cross-track push-broom elements are separate detectors, so it often is better to model their noise distributions independently. Thus, we apply an independent matched filter to each column of the (non-orthorectified) image, calculating a new $\boldsymbol{\mu}$ and $\boldsymbol{\Sigma}$ for each cross-track element. This columnwise matched filter dramatically reduces the number of samples available for estimating each $\boldsymbol{\Sigma}$. We compensate by estimating a stable, low-rank approximation of the inverse sample covariance as in Manolakis et al. (2009). The covariance matrix $\boldsymbol{\Sigma}$ decomposes as product of $p$ column eigenvectors $\boldsymbol{q}$ and $p$ eigenvalues $\phi$ :

$\boldsymbol{\Sigma}=\sum_{i=1}^{p} \phi_{i} \boldsymbol{q}_{i} \boldsymbol{q}_{i}^{T}$

The top $d$ eigenvalues approximate the inverse. With the identity matrix I and trace operator tr, we have

$$
\begin{aligned}
& \hat{\boldsymbol{\Sigma}}^{-1}=\frac{1}{\alpha}\left[\mathbf{I}-\sum_{i=1}^{d} \frac{\phi_{i}-\beta}{\phi_{i}} \boldsymbol{q}_{i} \boldsymbol{q}_{i}^{T}\right], \\
& \beta=\frac{1}{p-d}\left(\operatorname{tr} \boldsymbol{\Sigma}-\sum_{i=1}^{d} \phi_{i}\right) .
\end{aligned}
$$

We typically estimate 30 eigenvalues for vertical blocks consisting of 1000-2000 samples per column.

\subsection{Target signatures}

The signature $t$ should match the spectrum of the target feature. A reasonable approach is to use the transmission shape itself (the red curve in Fig. 2). However, this is inaccurate when absorption is strong; further attenuation becomes nonlinear as absorption lines saturate. The matched filter assumes a linear perturbation, so the Jacobian of the radiance spectrum is an appropriate signature. We calculate it by modeling local $\mathrm{CH}_{4}$ enhancement as a uniform cell. The airborne instrument measures absorption along a path transecting the $\mathrm{CH}_{4}$ cloud. For thin, uniform plumes, the unknown quantities of absorption length and concentration are interchangeable, so we consider the combined quantity, the mixing ratio length expressed in ppm m (Sandsten et al., 2000). Our derivation is similar to that of Theiler et al. (2005). Following Eq. (4) the matched filter estimates $\alpha$, which is a multiplicative scaling of the target signal that perturbs the mean background radiance $\boldsymbol{\mu}$. This background includes absorption by ambient $\mathrm{CH}_{4}$. Under hypothesis $H_{1}$, a local enhancement acts as a concentration-dependent absorption coefficient $\kappa(\lambda)$ and absorption path length $\ell$. For clarity, we write this relation with a functional form $\mu(\lambda)$ to represent a single wavelength of the mean vector $\mu$.

$H_{1}: L_{\mathrm{m}}(\lambda)=\mu(\lambda) e^{-\kappa(\lambda) \ell}$

For $x$ near zero, the first-order Taylor expansion $\exp (x) \approx$ $1+x$ permits

$H_{1}: L_{\mathrm{m}}(\lambda) \approx \mu(\lambda)-\kappa(\lambda) \ell \mu(\lambda)$.

Combining all wavelengths using vector notation, and folding unknowns into $\alpha$, yields

$H_{1}: \mathbf{L}_{\mathrm{m}} \approx \boldsymbol{\mu}+\boldsymbol{t}_{1} \alpha$.

This is the form of the matched filter model. The target signature $t_{1}$ is the vector of negative absorption coefficients for 
a near-surface plume of unit concentration and unit length, multiplied by the background mean radiance. The resulting matched filter estimates $\alpha$, the scaling of the unit concentration path length. The target signature represents the perturbation, in radiance units, of the background radiance by an additional unit mixing ratio length of $\mathrm{CH}_{4}$ absorption, which acts as a thin Beer-Lambert attenuation of the (already attenuated) background $\boldsymbol{\mu}$. Evaluating the partial derivative of Eq. (9) at $\ell=0$ gives

$$
\frac{\partial L_{\mathrm{m}}(\lambda)}{\partial l}=-\mu(\lambda) e^{-\kappa(\lambda) \ell} \kappa(\lambda)=-\mu(\lambda) \kappa(\lambda) .
$$

We can estimate the enhancement of $\mathrm{CH}_{4}$ using the linear scaling of a target signature that perturbs the mean radiance; that signature is defined as the negative absorption coefficient scaled by the (wavelength-dependent) radiance. Figure 2 compares the shape of the Jacobian target signature to the typical transmission signature of ambient $\mathrm{CH}_{4}$.

The linearization works for thin plumes even when the background is saturated, because deviations are small and can be modeled linearly to permit a fast yet accurate quantitative retrieval (Thorpe et al., 2013). It ignores scattering effects, which is a reasonable compromise at low flight altitudes; spectral features caused by actual $\mathrm{CH}_{4}$ enhancements by far exceed typical retrieval biases that could be induced by atmospheric scattering (Thorpe et al., 2013). In addition, Rayleigh and aerosol scattering is much lower in the $2.3 \mu \mathrm{m}$ region than in the $\mathrm{UV}$ and visible spectral range. The linearized approach is complementary to other more complete retrieval algorithms, such as the IMAP-DOAS approach (Frankenberg et al., 2005; Thorpe et al., 2014).

\subsection{Operator display}

After the detection stage maps plume intensities, an interface displays this information to the operator in a more tactically useful format. Specifically, the display overlays detected plumes on RGB images for visual interpretation and localization (Fig. 3). It supports variable detection thresholds so the operators can set the cutoff concentration according to their tolerance for false positives. This is important because source strength varies and the detection sensitivity changes with solar zenith angle. Also, it is important that the system preserve the overlay images in memory until explicitly reset, so that the operator has time to consider ambiguous detections. Figure 3 was produced by playing back a June flight line using a recent iteration of the detection software. A simple, intuitive interface minimizes unnecessary controls. A vertical slider scrolls the flight line to review previously collected data. During recording, the system appends data to the end of this image. A horizontal slider adjusts the detection threshold, allowing the operator to change the overlay sensitivity based on their tolerance for error. Bright red pixels signify a strong signal well above the threshold, while dark red pixels signify an ambiguous signal.

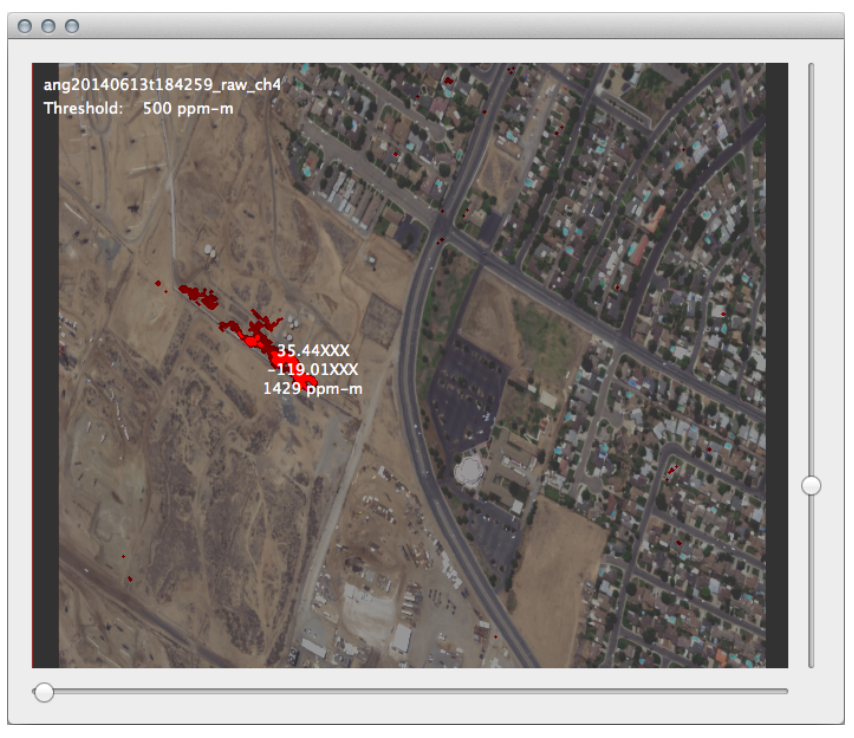

Figure 3. Screen shot of the graphical user interface, with an example of flight data from 13 June (ang20140613t184239). The red plume is displayed overprinted on RGB wavelengths. Real-time localization was implemented for use after the COMEX campaign, and we have redacted the precise coordinates in this image.

\section{Results from the COMEX campaign}

COMEX field data collection included the Kern River, Kern Front, and Poso Creek Oil Fields, located to the north and northwest of Bakersfield, CA in the San Joaquin Valley (Fig. 4). Along with AVIRIS-NG, the COMEX campaign deployed a second aircraft: the CIRPAS Twin Otter, which carried the Methane Airborne MAPper (MAMAP) (Gerilowski et al., 2011; Krings et al., 2011), a non-imaging spectrometer, and an in situ Picarro $\mathrm{CH}_{4}$ sensor sponsored by NASA, Ames. The campaign also deployed the AutoMObile greenhouse Gas Surveyor (AMOG) car-mounted system for in situ $\mathrm{CH}_{4}$ and wind measurement (Leifer et al., 2014). These platforms used several real-time displays and communications links. AMOG used a map overlay (Google Earth, 2015) displaying $\mathrm{CH}_{4}$ measurements along with the wind direction. MAMAP was modified for COMEX to deliver real-time retrieved $\mathrm{CH}_{4}$ information using a WFM-DOAS algorithm described in Krings et al. (2011, 2013). These data were displayed on the MAMAP instrument scientist aboard the aircraft, and overlaid on a map (Google Earth, 2015) for tactical decision making. MAMAP also transmitted its real-time $\mathrm{CH}_{4}$ measurements together with telemetry and data from other CIRPAS sensors to the CIRPAS data acquisition and assimilation system, where they were downlinked by satellite to the command center. All aircraft were tracked during the mission using the Airborne Science Mission Tools Suite (Duley et al., 2011), the ground segment to the NASA Airborne Science Sensor Network (Van Gilst and Sorenson, 2011). This system provided a web-based service for real-time communications 


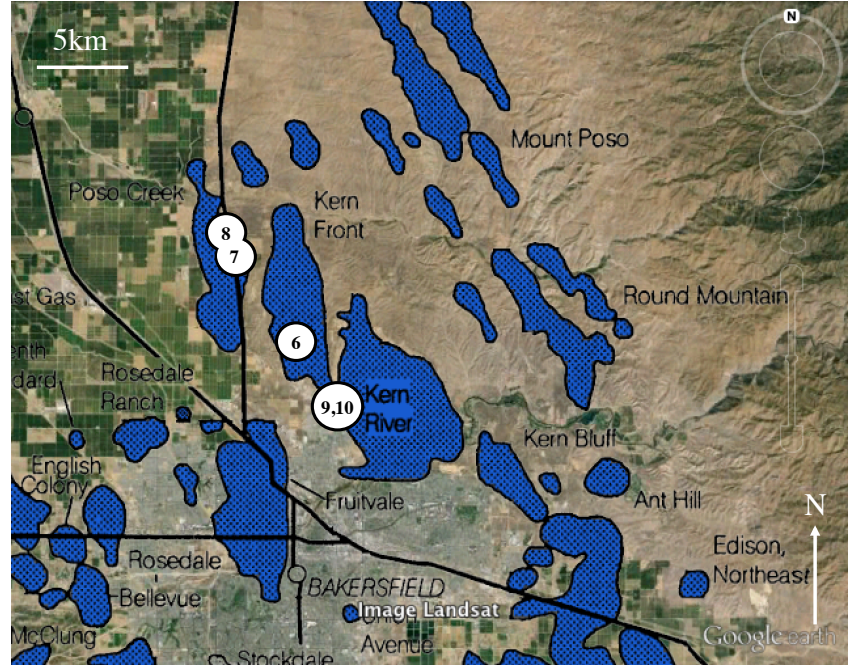

Figure 4. Kern Oil Fields, Bakersfield, CA (Google Earth, 2015). Oil field locations are from California Department of Conservation (1998). White circles indicate the locations of Figs. 6-10.

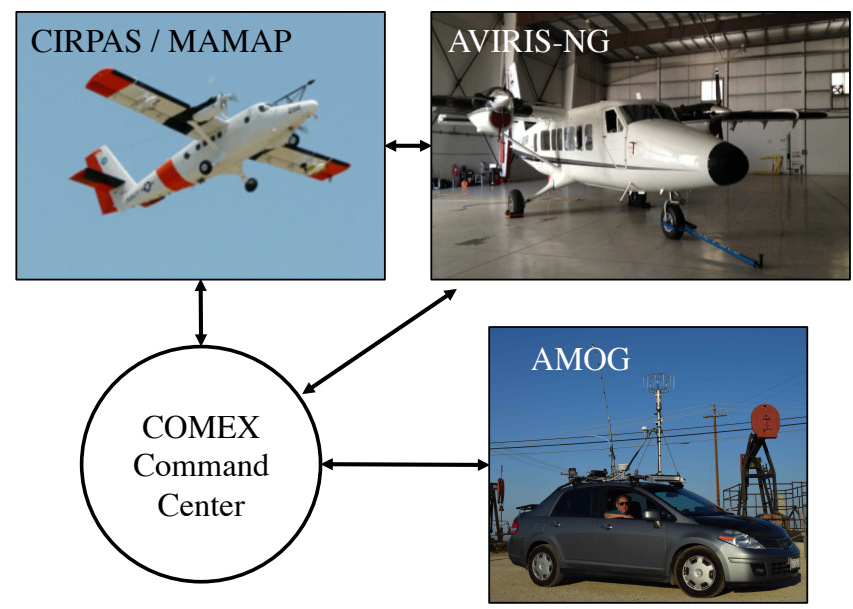

Figure 5. The three platforms in the COMEX campaign coordinated their activities through the central command center. The two aircraft also communicated directly. CIRPAS image from www. cirpas.org. AMOG image by I. Leifer.

between aircraft operators and the science team (Fig. 5). It also integrated real-time aircraft position and state information through a common map display.

We focus here on 3 days when all sensors and platforms were active in the field: 13 June, 2 September, and 4 September 2014. During the June investigation only MAMAP was analyzed in real time; AVIRIS-NG $\mathrm{CH}_{4}$ detection took place offline. We later installed the band ratio algorithm and used it onboard AVIRIS-NG in September, where it operated successfully. Finally, the full columnwise matched filter for $\mathrm{CH}_{4}$ was developed and installed after the campaign, and used in post-analysis.
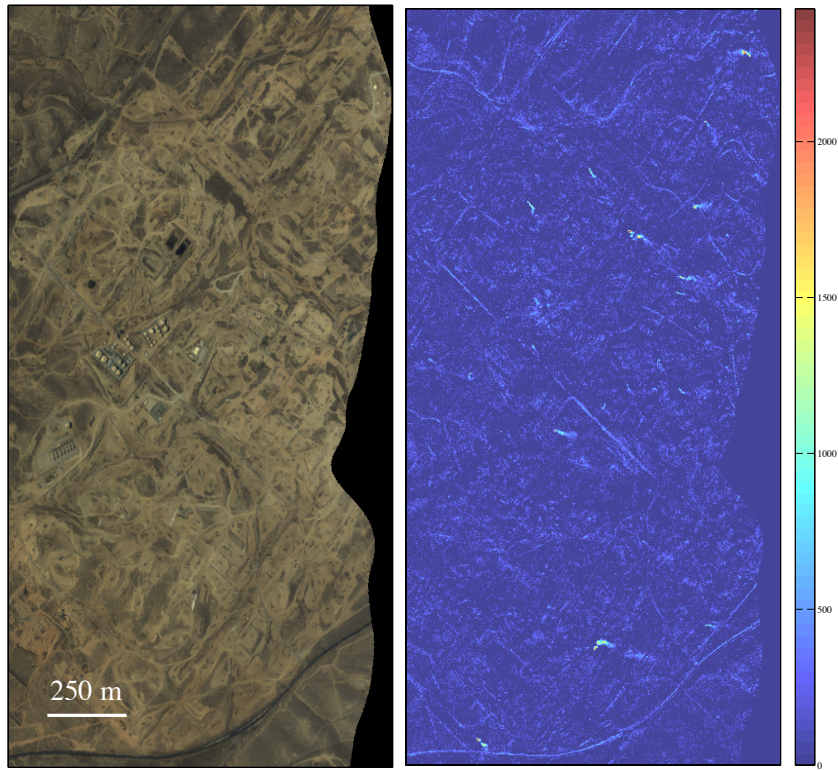

Figure 6. Region of high activity in flight line 2 of the 2 September flight lines. All values in ppm m.

\subsection{Operational implementation of tactical remote measurement}

AVIRIS-NG flew along six neighboring flight lines. Tactical remote measurement was implemented during the 2 September data acquisition, and detected many "hot spots" of high $\mathrm{CH}_{4}$ concentrations. Operators noted strong plumes on flight lines 2 and 3, on the west side of the study area, and relatively weak activity on the east side. AVIRIS-NG operators transmitted plume coordinates to the ground team by text message via the command center. The MAMAP and AVIRIS-NG aircraft also shared their observations using direct radio communications. Flight line 2, recorded in flight as having the largest number of hits, was revealed by post-analysis to contain patches of high activity (Fig. 6). The final data acquisitions focused on this flight line, which comprised three of the final nine images. Focusing on the west side significantly increased the total plumes imaged for the day, and also provided improved data on temporal variability.

Operations on 4 September made further use of real-time AVIRIS-NG and MAMAP data. As before, the flight lines contained many active plumes. However, the ground team's initial data collection at the Kern River oil field did not show significant $\mathrm{CH}_{4}$. The ground team coordinator suggested shifting data collection west to the Kern Front Oil Field. AVIRIS-NG confirmed the presence of $\mathrm{CH}_{4}$ plumes in this area, and the experiment coordinator rerouted the surface teams. The surface teams relocated and identified an exceptionally strong $\mathrm{CH}_{4}$ plume coming from the direction of a drilling rig, approximately $1 \mathrm{~km}$ from the road. Subsequent analysis of AVIRIS-NG data indicated a plume in this 

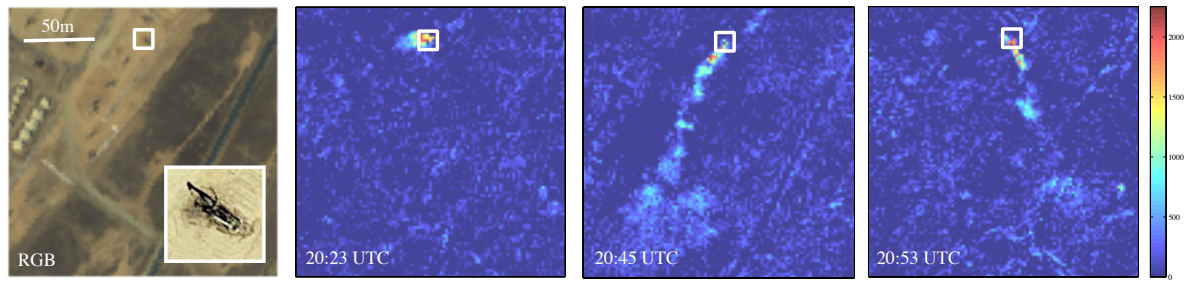

Figure 7. Left: subframe of ang20140904t205356. The insert (Google Earth, 2015) is a high-resolution visible image that reveals the source to be a pump jack. The proceeding panels, from left to right, show repeat overflights at 20:23, 20:45, and 20:53 UTC. Values show local $\mathrm{CH}_{4}$ enhancement in ppm m.

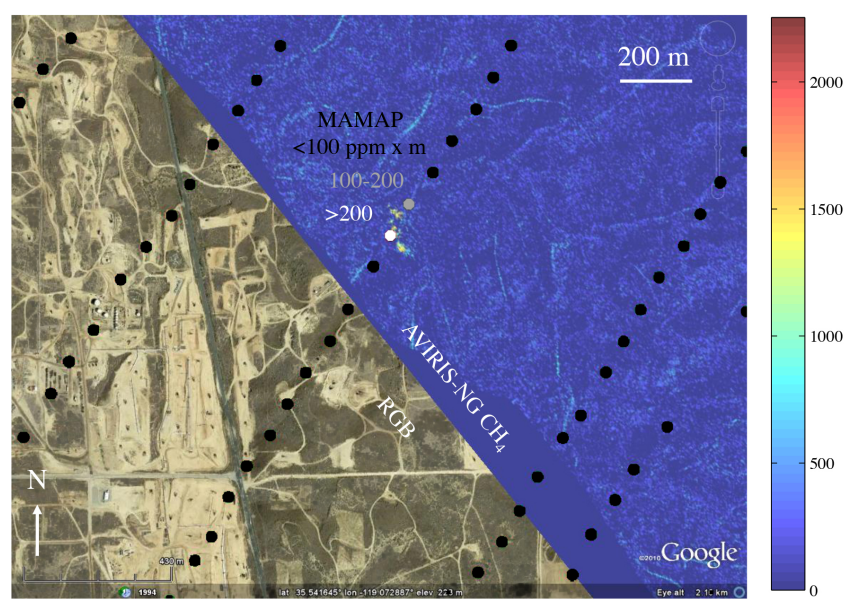

Figure 8. Example of MAMAP soundings overlaid on an AVIRIS-NG detection result. Colored pixels indicate $\mathrm{CH}_{4}$ mixing ratio lengths in $\mathrm{ppm} \mathrm{m}$ from AVIRIS-NG. The monochrome dots show MAMAP soundings: black signifies $<100 \mathrm{ppmm}$, grey $100-200 \mathrm{ppm} \mathrm{m}$, and white $>200 \mathrm{ppm} \mathrm{m}$. Overlay courtesy Google Earth (2015).

area that originated at a small structure about $100 \mathrm{~m}$ from the road. The real-time MAMAP data also observed a large scale plume originating from that area (Gerilowski et al., 2014).

Thanks to the tactical remote sensing, AVIRIS-NG continued covering this area with repeat overflights at $10-20 \mathrm{~min}$ intervals that revealed the temporal evolution of many plume features. Figure 7 shows a sequence of revisits to one of the stronger targets. Commercial satellite imagery from Google Earth reveals the source, a pump jack (Google Earth, 2015). The AVIRIS-NG data shows strong $\mathrm{CH}_{4}$ absorption near the source, which would be expected for a vertical rise by a buoyant column. Turbulence causes the plume structure to become discontinuous as it disperses downwind. The matched filter resolves the plume at concentrations as low as $500 \mathrm{ppm} \mathrm{m}$, approximately 3 standard deviations above the background noise.

Figure 8 shows the agreement between the different instruments on 4 September. Colored pixels indicate $\mathrm{CH}_{4}$ mixing ratio lengths from AVIRIS-NG. The monochrome dots show MAMAP retrievals: black signifies the background up
Table 1. Selected flight days in the COMEX campaign. Often AVIRIS-NG overflew the same plume multiple times. Here the "Plumes" column records the total number of instances that a plume appears in the data, rather than the number of physical plumes.

\begin{tabular}{llll}
\hline Date & Real-time analysis & Flight lines & Plumes \\
\hline 13 Jun 2014 & No & 26 & 29 \\
2 Sep 2014 & Yes & 17 & 68 \\
4 Sep 2014 & Yes & 25 & 57 \\
\hline
\end{tabular}
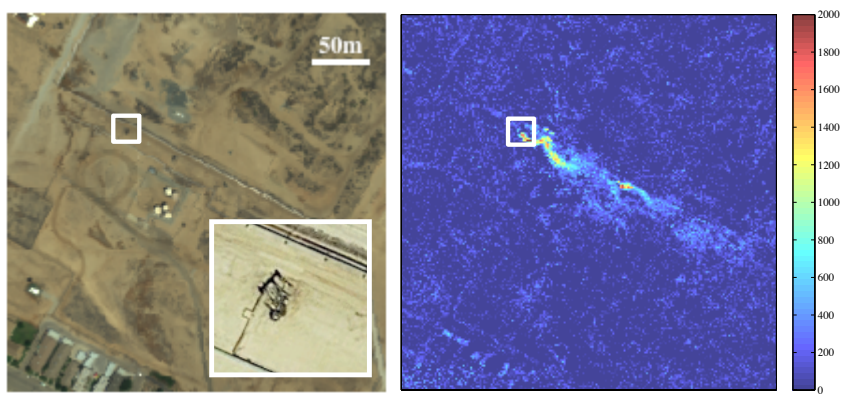

Figure 9. Left: RGB wavelengths of a June 13 AVIRIS-NG overflight (ang20140613t184239). The insert shows a high-resolution visible image of the pump jack (Google Earth, 2015). Right: retrieved $\mathrm{CH}_{4}$ enhancement in ppm $\mathrm{m}$, using the Jacobian signature.

to $<100 \mathrm{ppm} \mathrm{m}$. A grey dot shows $\mathrm{CH}_{4}$ of $100-200 \mathrm{ppm} \mathrm{m}$ near the plume, and a single white dot shows $\mathrm{CH}_{4}$ exceeding $200 \mathrm{ppm} \mathrm{m}$ within the plume. There are several reasons why retrievals might differ. First, the two instruments have disparate spatiotemporal coverage; on 4 September the MAMAP cross track instantaneous field of view is $86, \mathrm{~m}$ $\left(2.9^{\circ}\right)$, and the down track instantaneous field of view is $76 \mathrm{~m}$ $\left(2.64^{\circ}\right)$, with additional down track averaging of $48 \mathrm{~m}$ during the integration time. Moreover, the acquisition time difference of several minutes is significantly longer than variability in wind speed and gusts due to local atmospheric turbulence at relevant spatial scales of $<500 \mathrm{~m}$. Emissions have been documented to vary on similar timescales. Finally, the optical paths differ so concentration measurements are not perfectly comparable. 

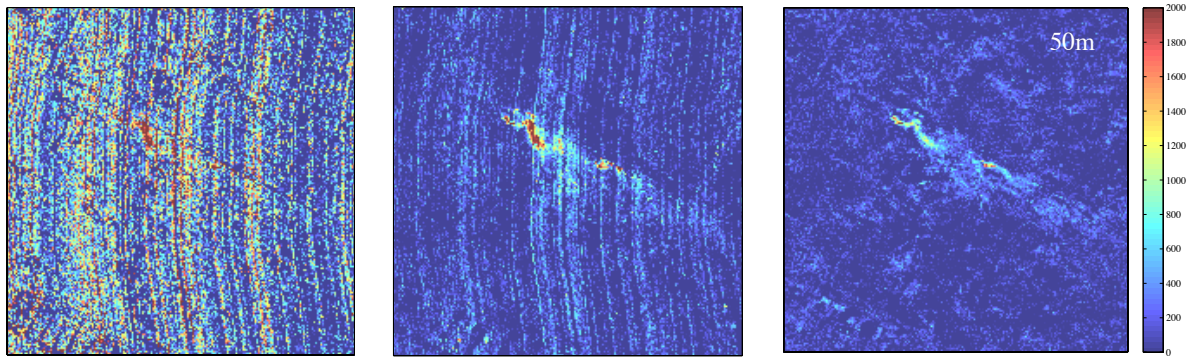

Figure 10. Left: band ratio method applied to flight line ang20140613t184239. Center: classical matched filter with transmission signature. Right: columnwise matched filter with transmission signature. Values show local $\mathrm{CH}_{4}$ enhancement in $\mathrm{ppm} \mathrm{m}$.

With these caveats in mind, we directly compared the two measurements. We calculated a spatially weighted average of the AVIRIS-NG estimated enhancement above background, matching it to the MAMAP response while simultaneously searching over the sounding's position uncertainty radius of $50 \mathrm{~m}$. The resulting estimates were as high as $103.5 \mathrm{ppm} \mathrm{m}$ (white dot) and $101.3 \mathrm{ppm} \mathrm{m}$ (grey dot), of similar magnitude to the MAMAP retrievals. Despite differences in observing conditions, both data sets evidence similar-scale enhancements at this site. In other cases, small plumes visible in AVIRIS-NG were sometimes invisible in MAMAP data.

Table 1 summarizes the total number of plume instances appearing in each day's data, as revealed in post-analysis of AVIRIS-NG data. We record only the unambiguous detections with a long axis greater than five pixels, and exclude compact detections from becalmed image segments - their bright, concentrated plumes show a strong signal but lack the morphological cues needed for unambiguous attribution.

\section{2 $\mathrm{CH}_{4}$ detection sensitivity}

We use the 13 June flight lines as a control case to evaluate sensitivity, because the tactical remote sensing system was not operational; i.e., data collection was "blind." Figure 9 shows a typical map of plume thicknesses in $\mathrm{ppm} \mathrm{m}$. Retrieved values approach $2500 \mathrm{ppm}$. A defined plume is evident, along with turbulent structures that disperse 100 $200 \mathrm{~m}$ downwind of the source. The insert shows a highresolution visible image, which reveals the source to be a pump jack. Figure 10 shows the same scene analyzed with alternative algorithms: band ratio, matched filter, and columnwise matched filter detection strategies respectively, with intensities scaled to the maximum on-plume pixel. The band ratio barely reveals the largest plumes with many contiguous "hot" pixels. A classical matched filter improves performance and the columnwise version is cleaner still. One gleans a final SNR benefit using the Jacobian rather than the transmission as a target signature.

We evaluated detection sensitivity by exhaustively labeling all $\mathrm{CH}_{4}$ plumes in the 13 June flight lines by manual inspection. There were 29 obvious plumes, some of which were repeat overflights of the same physical location. For each plume, we identified 3-10 on-plume pixels having the highest estimated concentration. We then calculated SNR using a large rectangular region of pixels $100 \mathrm{~m}$ upwind as the background. Figure 11 shows the relationship between plume strength (in units of $\mathrm{ppm} \mathrm{m}$ ) and SNR. The dark lines of best fit are constrained to intersect the origin. Table 2 reports these slopes $\alpha$ and the reciprocal, the noise equivalent mixing ratio length (NEMRL), defined here as 1 standard deviation above the background. The first three rows show a CIBR method, a classical matched filter based on the transmission spectrum, but applied columnwise, and a more traditional matched filter with rectangular support but using the Jacobian spectrum. The fourth row shows the columnwise Jacobian matched filter. This combination achieves a NEMRL of $140 \mathrm{ppm} m$ the best overall performance of any algorithm.

We have defined sensitivities in terms of ppm $\mathrm{m}$ at standard temperature and pressure (STP), which is a reasonable approximation for the Kern fields. However, one could also express sensitivity as a fractional enhancement of the entire atmospheric column. To calculate this value, we average the seasonal and geographic $\mathrm{CH}_{4}$ profiles of Matricardi (2003), which incorporate tropospheric models from Müller and Brasseur (1995) and Clerbaux et al. (1998). The resulting column has an STP-equivalent mixing ratio length of $14600 \mathrm{ppm} \mathrm{m}$ for which the noise-equivalent enhancement is $1 \%$. A larger total-column enhancement of $3.4 \%$ would be equivalent to $500 \mathrm{ppm} \mathrm{m}$, producing a strong $>3 \sigma$ detection.

The SNRs reported here understate the effective system sensitivity when paired with a trained operator. SNR estimates assume pixel independence, but in practice plumes show multiple contiguous pixels, none of which need to be above the standard 3-5 $\sigma$ detection limit to distinguish the structure as a whole. Consequently plumes with strengths near the noise floor were visually apparent. The SNR disregards contaminating clutter, such as painted structures with similar absorption features, which could cause localized false positives. However, such features were rare; they occurred at most a few times per flight line. Moreover, they were generally easy to ignore by eye because their sizes and morphologies were very distinct from plumes. Consequently false positives were not a significant problem during actual use. 

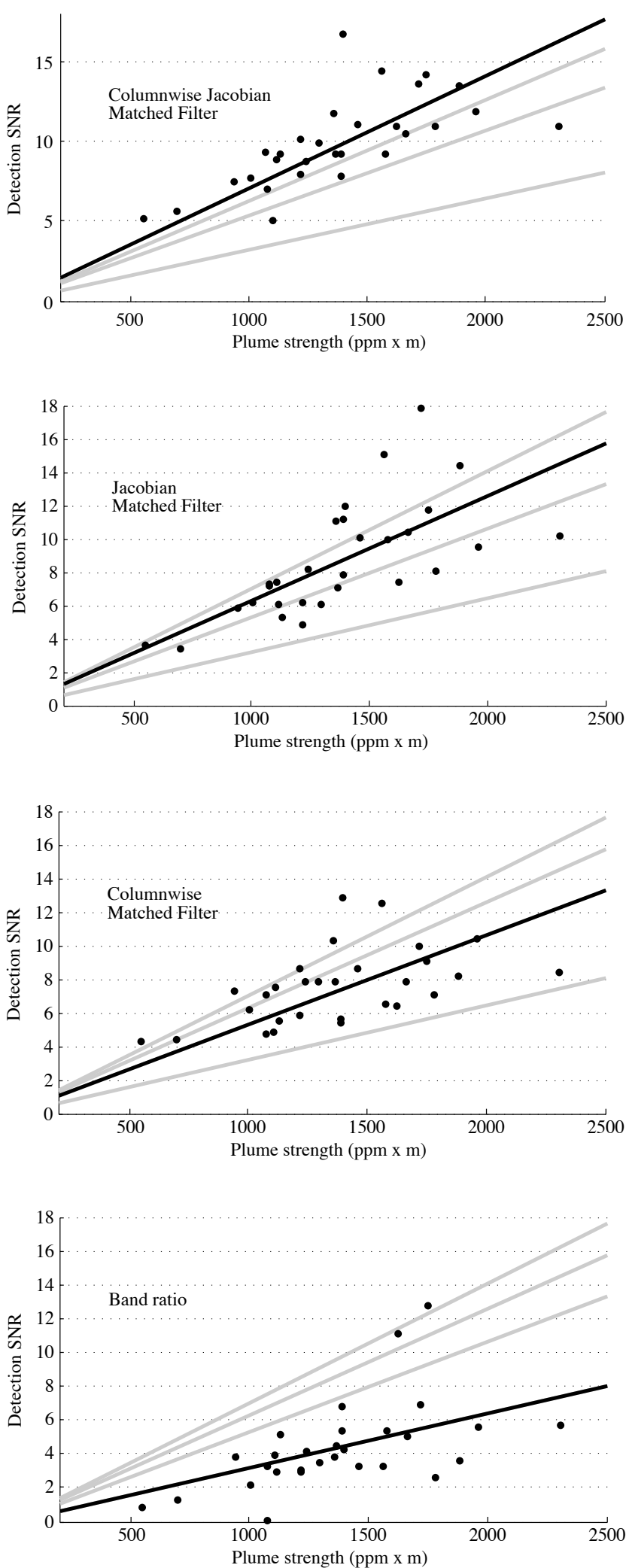

Figure 11. Plume strength vs. detection SNR for four different methods, applied to the 29 plumes observed in 13 June flight lines.
Table 2. Detection sensitivity for band ratio and matched filter (MF) methods. Columns show the noise-equivalent mixing ratio lengths expressed as ppm m and as $\mathrm{CH}_{4}$ column enhancements.

\begin{tabular}{lrrr}
\hline Method & $\alpha$ & $\begin{array}{r}\text { NEMRL } \\
(\mathrm{ppm} \mathrm{m})\end{array}$ & $1 \sigma$ Enhanc. \\
\hline Band Ratio & 0.0032 & 310 & $2.1 \%$ \\
Columnwise MF & 0.0053 & 187 & $1.3 \%$ \\
Jacobian MF & 0.0063 & 159 & $1.1 \%$ \\
Jacobian Columnwise MF & 0.0071 & 141 & $1.0 \%$ \\
\hline
\end{tabular}

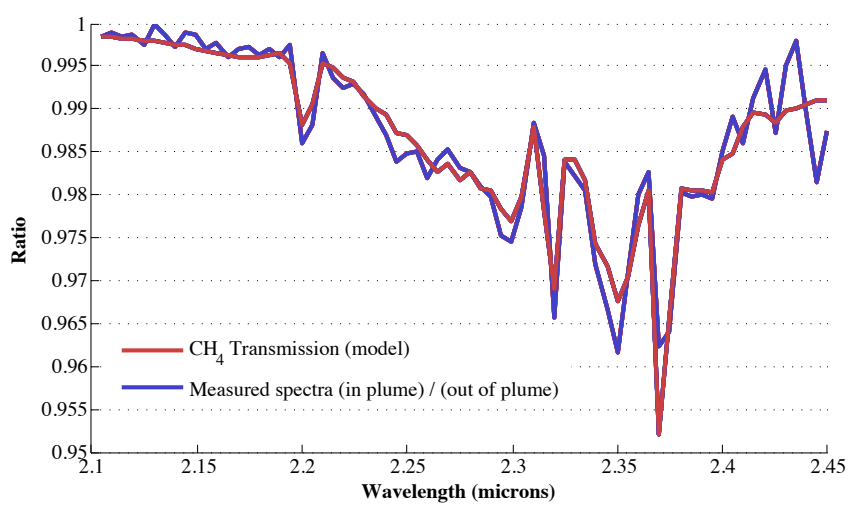

Figure 12. Typical ratio of radiances in the plume and out of plume. The ratio is continuum-removed, with an offset and vertical scaling to highlight the similar shapes.

We used several methods to verify that detections were actually caused by $\mathrm{CH}_{4}$, and not false positives due to interfering surface features or gases. First, a visual assessment verified that the source location of each plume lay near artificial structures, as expected, and that its main structure was uncorrelated with visible surface features or changes in albedo. In other words, the plumes were contiguous phenomena that crossed rather than followed the boundaries of surface features. Second, for a subset of plumes, we verified that the ratio of in-plume and background radiances showed a clear $\mathrm{CH}_{4}$ signature. Figure 12 illustrates this process for the plume in Fig. 9. The figure shows the ratio of the average radiance spectra, further divided by the linear continuum stretching across the two endpoints of the spectral interval. The plot compares this ratio to the modeled transmittance of $\mathrm{CH}_{4}$. The model fits three parameters consisting of a linear continuum and the absorption given by the mixing ratio length. The retrieved path length of $2438 \mathrm{ppm} \mathrm{m}$ is a close match to the linear solution from the matched filter, and the resulting spectrum is a good fit to the empirical ratio. This provides additional confidence that the detection was due to the actual presence of $\mathrm{CH}_{4}$ and not (for example) a false positive artifact. Motivated by the use of steam injection for enhanced oil recovery at Bakersfield, we checked the ratios for $\mathrm{H}_{2} \mathrm{O}$ vapor absorption and failed to find any excess concentration of this potential interferant. Finally, corroborative 
measurements by other COMEX in situ and remote sensing instruments confirmed the presence of $\mathrm{CH}_{4}$, as illustrated in Fig. 8.

\subsection{Discussion}

These experiments underscore the value of merging diverse instruments with partial overlap in measurement capabilities. This overlap permits the instruments to cross-check each other, and allows fast mapping platforms to provide reconnaissance to in situ teams. For example, COMEX used a multi-tier strategy of nested measurement scales. At the top level, MAMAP provided high accuracy retrievals over very wide areas, and resolved $\mathrm{CH}_{4}$ plumes on the scale of hundreds of meters. Airborne in situ measurements provided validation of remotely observed large scale plumes. AVIRIS-NG provided unambiguous images of specific plume sources, locating them to within a few meters. The ground team augmented this remote view with in situ point samples. The arrangement proved effective, but relied on a relatively slowmoving ground team to close the loop with unambiguous in situ measurements. Tactical remote measurement with efficient airborne reconnaissance makes full use of these in situ instruments.

There are several logical next steps for both hardware and software development. For hardware, a future instrument designed specifically for the purposes of $\mathrm{CH}_{4}$ would offer far better detection performance. For example, an imaging spectrometer that focused just on the $2.1-2.4 \mu \mathrm{m}$ range would permit much finer spectral resolution for highly sensitive and accurate retrievals. A slower, low-flying platform would provide higher spatial resolution and improved SNR. On software, COMEX revealed a need for a real-time geolocalization capability to display accurate plume locations. This capability has since been implemented using a geometric camera model, geometric ray-tracing, and an onboard digital elevation model (DEM). One could further mitigate clutterrelated noise with more sophisticated background modeling (Funk et al., 2001; Thorpe et al., 2013) or explicit outlier rejection (DiPietro et al., 2012; Boardman and Kruse, 2011). Finally, the system could be made more general by pairing it with the real-time reflectance processing (Bue et al., 2015) to recognize materials at the surface in addition to gaseous absorbers. This would expand missions to applications including search and rescue, tracking of spatially variable phytoplankton or algal blooms for water color studies, fire response, and oil spill response.
During COMEX, communicating tactical science data across platforms improved science outcomes and produced a robust data set that could be used to validate interpretations. Advanced communications infrastructure can further streamline data transfer between ground and flight. The NASA Airborne Science Data and Telemetry system (Sorenson et al., 2011) functions as a flight data recorder, onboard payload network server, and low bandwidth telemetry system. A Payload Telemetry Link Module augments this system with higher level data products and high bandwidth satellite telemetry. Similar systems can be used to more seamlessly share data across participants. As the number of realtime data products increases, it becomes important to avoid information overload. Displaying data as optional map layers provides user control, while chat capabilities allow different team members to flag important observations.

\section{Conclusions}

We have demonstrated tactical signature detection onboard AVIRIS-NG in service of a coordinated science campaign, COMEX. Informing the operators when $\mathrm{CH}_{4}$ plumes were detected improved the science yield of this investigation, both by confirming data quality in real time and by enabling more flexible asset deployment. Post-analysis demonstrated that the strongest detected signatures were related to real sources. The latest iteration of the system provides $3 \sigma$ detection sensitivity of $500 \mathrm{ppm} \mathrm{m}$ or weaker. 

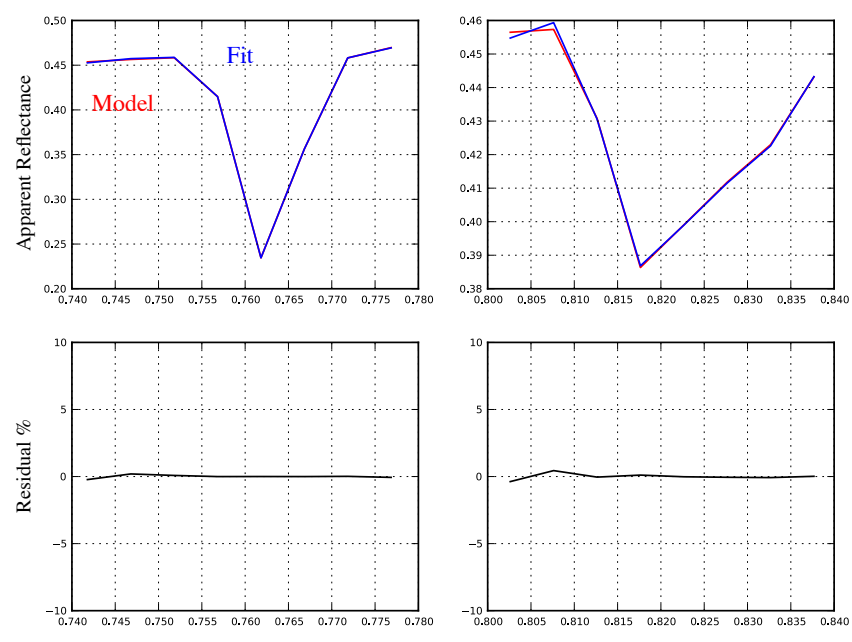

Wavelength (microns)

Wavelength (microns)

Figure A1. Wavelength calibration: empirical fits to the $0.76 \mu \mathrm{m}$ oxygen band and $0.82 \mu \mathrm{m}$ water vapor band.

\section{Appendix A: Wavelength calibration}

Accurate wavelength calibration is critical for detecting narrow spectral absorption features. Our wavelength calibration uses laser sources to characterize the center wavelengths and and full width half maximum (FWHM) of the detector array. This initial wavelength calibration is derived from six sources (at $0.4067,0.532,0.632,1.064,1.551$, and $2.064 \mu \mathrm{m})$. We refine this result with flight data, optimizing a single uniform shift to match atmospheric absorption features in the top of atmosphere (TOA) reflectance spectrum $\rho(c, \lambda)$. Following Gao et al. (1993b), the TOA reflectance represents the radiance measurements at wavelengths $\lambda$, after normalizing for extra-terrestrial solar irradiance $F$ and solar zenith $\theta$ :

$\rho(c, \lambda)=\frac{\pi L_{\mathrm{m}}(c, \lambda)}{F(\lambda) \cos (\theta)}$.

We model this spectrum as a locally linear continuum attenuated by gaseous absorption of the $0.74 \mu \mathrm{m}$ oxygen band and the 0.96 and $1.14 \mu \mathrm{m}$ water vapor bands. The attenuation is governed by a Beer-Lambert relation based on the gas absorption coefficient $\delta(\lambda)$ obtained from a 20 layer model atmosphere:

$\hat{\rho}(\lambda)=h\left(\tau_{1}\right)\left[\tau_{2} e^{-\tau_{3} \delta\left(\tau_{4}+\lambda\right)}+\tau_{5}\left[\tau_{4}+\lambda\right]\right]$,

where $\tau$ represents free parameters we optimize during the fit. Specifically, $h\left(\tau_{1}\right)$ is convolution with a Gaussian spectral response function with a FWHM given by $\tau_{1} . \tau_{2}$ is the continuum level at $100 \%, \tau_{3}$ represents the absorption path length, $\tau_{4}$ the wavelength shift and $\tau_{5}$ a linear slope. We fit these free parameters using a Nelder-Mead simplex algorithm. Figure A1 (Right) shows an example from a bright,

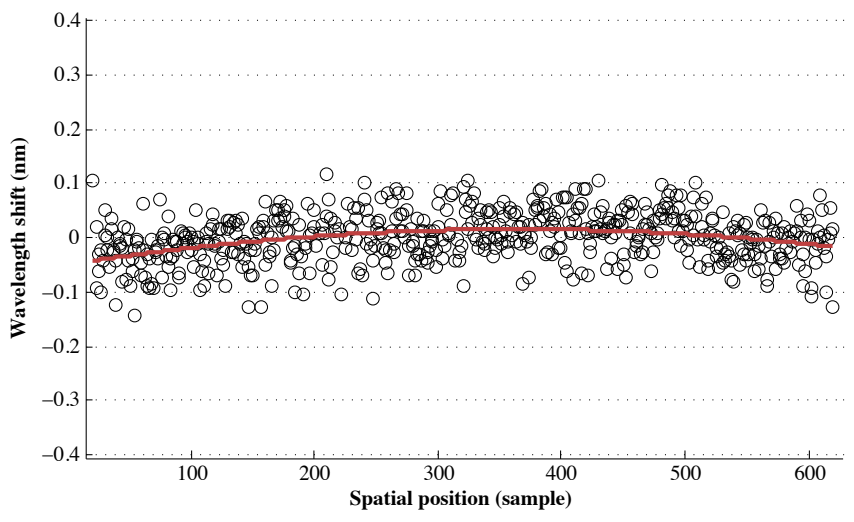

Figure A2. Wavelength calibration: cross-track divergence characterized by the position of the oxygen A band over Ivanpah Playa, NV.

spectrally smooth playa. Here the model matches the measured spectrum with residual error under $1 \%$ - within the limits of the spectrometer's radiometric accuracy. The empirical calibration procedure is an independent check of crosstrack spectral uniformity. Figure A2 shows the wavelength calibration shift for different cross-track elements, after averaging 500 downtrack samples in each column. The average shift is less than $0.1 \mathrm{~nm}$, or $2 \%$ of the full width at half maximum. 
Acknowledgements. We acknowledge and thank the AVIRIS-NG team, as well as scientists at JPL and elsewhere whose counsel was invaluable throughout the system design process: Andrew Aubrey, Lance Christensen, Dar A. Roberts. Brian Bue (JPL) is the original author of the real-time infrastructure that formed the foundation of the new AVIRIS-NG system. A portion of the research described in this paper was performed by the Jet Propulsion Laboratory, California Institute of Technology, under a contract with the National Aeronautics and Space Administration. The author's copyright for this publication has been transferred to the California Institute of Technology. The Government sponsorship is acknowledged.

Edited by: U. Platt

\section{References}

Ambrosia, V., Wegener, S., Zajkowski, T., Sullivan, D., Buechel, S., Enomoto, F., Lobitz, B., Johan, S., Brass, J., and Hinkley, E.: The Ikhana unmanned airborne system (UAS) western states fire imaging missions: from concept to reality (2006-2010), Geocarto International, 26, 85-101, 2011.

Ambrosia, V. G., Wegener, S. S., Sullivan, D. V., Buechel, S. W., Dunagan, S. E., Brass, J. A., Stoneburner, J., and Schoenung, S. M.: Demonstrating UAV-acquired real-time thermal data over fires, Photogramm. Eng. Rem. S., 69, 391-402, 2003.

Aubrey, A., Frankenberg, C., Green, R., Eastwood, M., Thompson, D., and Thorpe, A. K.: Crosscutting airborne remote sensing technologies for oil and gas and Earth science applications, in: Offshore Technology Conference, Houston, Texas, USA, 2015.

Boardman, J. W. and Kruse, F. A.: Analysis of imaging spectrometer data using n-dimensional geometry and a mixture-tuned matched filtering approach, IEEE T. Geosci. Remote, 49, 41384152, 2011.

Bojinski, S., Schlaepfer, D., Schaepman, M. E., and Keller, J.: Aerosol mapping over rugged heterogeneous terrain with imaging spectrometer data, in: International Symposium on Optical Science and Technology, International Society for Optics and Photonics, 108-119, 2002.

Bradley, E. S., Leifer, I., Roberts, D. A., Dennison, P. E., and Washburn, L.: Detection of marine methane emissions with AVIRIS band ratios, Geophys. Res. Lett., 38, doi:10.1029/2011GL046729, 2011.

Braun, S. A., Kakar, R., Zipser, E., Heymsfield, G., Albers, C., Brown, S., Durden, S. L., Guimond, S., Halverson, J., Heymsfield, A., Ismail, S., Lambrigtsen, B., Miller, T., Tanelli, S., Thomas, J., and Zawislak, J.: NASA's Genesis and Rapid Intensification Processes (GRIP) field experiment, B. Am. Meteorol. Soc., 94, 345-363, 2013.

Brown, L., Sung, K., Benner, D., Devi, V., Boudon, V., Gabard, T., Wenger, C., Campargue, A., Leshchishina, O., Kassi, S., Mondelain, D., Wang, L., Daumont, L., Régalia, L., Rey, M., Thomas, X., Tyuterev, V. G., Lyulin, O. M., Nikitin, A. V., Niederer, H. M., Albert, S., Bauerecker, S., Quack, M., O’Brien, J. J., Gordon, I. E., Rothman, L. S., Sasada, H., Coustenis, A., Smith, M. A. H., Carrington Jr., T., Wang, X.-G., Mantz, A. W., and Spickler, P. T.: Methane line parameters in the HITRAN2012 database, J. Quant. Spectrosc. Ra., 130, 201-219, 2013.
Bruegge, C. J., Conel, J. E., Margolis, J. S., Green, R. O., Toon, G. C., Carrere, V., Holm, R. G., and Hoover, G.: In-situ atmospheric water-vapor retrieval in support of AVIRIS validation, P. Soc. Photo-Opt. Ins., 1298, 150-163, 1990.

Bue, B. D., Thompson, D. R., Eastwood, M., Green, R. O., Gao, B., Keymeulen, D., Sarture, C. M., Mazer, A. S., and Luong, H. H.: Real-time atmospheric correction of AVIRISNG imagery, IEEE T. Geosci. Remote, 53, 6419-6428, doi:10.1109/TGRS.2015.2439215, 2015.

California Dept. Conservation, Departement of Gas, and Geothermal Resources, California Oil \& Gas Fields: Volume 1 - Central California, Technical Report Number TR10-12, p. 499, Index Map D., California Dept. Conservation, Sacramento CA, USA, Fig. 10 caption: "inferred from AVIRIS-NG" - "from AVIRISNG', 1998 .

Chang, C.-I. and Chiang, S.-S.: Anomaly detection and classification for hyperspectral imagery, IEEE T. Geosci. Remote, 40, 1314-1325, 2002.

Clark, R. N., Curchin, J. M., Hoefen, T. M., and Swayze, G. A.: Reflectance spectroscopy of organic compounds: 1. Alkanes, J. Geophys. Res.-Planet., 114, doi:10.1029/2008JE003150, 2009.

Clark, R. N., Swayze, G. A., Leifer, I., Livo, K. E., Kokaly, R., Hoefen, T., Lundeen, S., Eastwood, M., Green, R. O., Pearson, N., Sarture, C., McCubbin, I., Roberts, D., Bradley, E., Steele, D., Ryan, T., Dominguez, R., and the Air borne Visible/Infrared Imaging Spectrometer (AVIRIS) Team: A method for quantitative mapping of thick oil spills using imaging spectroscopy, US Geological Survey, Reston, VA, USA, Open-File Report, 1167, 1-51, 2010.

Clerbaux, C., Chazette, P., Hadji-Lazaro, J., Mégie, G., Müller, J.F., and Clough, S.: Remote sensing of $\mathrm{C}_{O}, \mathrm{CH}_{4}$, and $\mathrm{O}_{3}$ using a spaceborne nadir-viewing interferometer, J. Geophys. Res.Atmos., 103, 18999-19013, 1998.

Davis, S., Hlavka, D., Jensen, E., Rosenlof, K., Yang, Q., Schmidt, S., Borrmann, S., Frey, W., Lawson, P., Voemel, H., and Voemel, T. P.: In situ and lidar observations of tropopause subvisible cirrus clouds during TC4, J. Geophys. Res.-Atmos., 115, D00J17, doi:10.1029/2009JD013093, 2010.

Dennison, P. E. and Roberts, D. A.: Daytime fire detection using airborne hyperspectral data, Remote Sens. Environ., 113, 16461657, 2009.

Dennison, P. E., Thorpe, A. K., Pardyjak, E. R., Roberts, D. A., Qi, Y., Green, R. O., Bradley, E. S., and Funk, C. C.: High spatial resolution mapping of elevated atmospheric carbon dioxide using airborne imaging spectroscopy: radiative transfer modeling and power plant plume detection, Remote Sens. Environ., 139, 116129, 2013.

DiPietro, R. S., Manolakis, D. G., Lockwood, R. B., Cooley, T., and Jacobson, J.: Hyperspectral matched filter with false-alarm mitigation, Opt. Eng., 51, 016202, doi:10.1117/1.OE.51.1.016202, 2012.

Duley, A. R., Sullivan, D., Fladeland, M. M., Myers, J., Craig, M., Enomoto, F., Van Gilst, D. P., and Johan, S.: The COMPASS Project, AGU Fall Meeting Abstracts, B1574, available at: http:// adsabs.harvard.edu/abs/2011AGUFMIN51B1574D (last access: 12 June 2015), 2011 
Eismann, M., Stocker, A., and Nasrabadi, N.: Automated hyperspectral cueing for civilian search and rescue, Proceedings of the IEEE, 97, 1031-1055, 2009.

Frankenberg, C., Platt, U., and Wagner, T.: Iterative maximum a posteriori (IMAP)-DOAS for retrieval of strongly absorbing trace gases: Model studies for $\mathrm{CH}_{4}$ and $\mathrm{CO}_{2}$ retrieval from near infrared spectra of SCIAMACHY onboard ENVISAT, Atmos. Chem. Phys., 5, 9-22, doi:10.5194/acp-5-9-2005, 2005.

Funk, C., Theiler, J., Roberts, D., and Borel, C.: Clustering to improve matched filter detection of weak gas plumes in hyperspectral thermal imagery, IEEE T. Geosci. Remote, 39, 1410-1420, 2001.

Gao, B.-C., Goetz, A. F., and Wiscombe, W. J.: Cirrus cloud detection from airborne imaging spectrometer data using the $1.38 \mu \mathrm{m}$ water vapor band, Geophys. Res. Lett., 20, 301-304, 1993a.

Gao, B. C., Heidebrecht, K. B., and Goetz, A. F.: Derivation of scaled surface reflectances from AVIRIS data, Remote Sens. Environ., 44, 165-178, 1993b.

Gerilowski, K., Tretner, A., Krings, T., Buchwitz, M., Bertagnolio, P. P., Belemezov, F., Erzinger, J., Burrows, J. P., and Bovensmann, H.: MAMAP - a new spectrometer system for columnaveraged methane and carbon dioxide observations from aircraft: instrument description and performance analysis, Atmos. Meas. Tech., 4, 215-243, doi:10.5194/amt-4-215-2011, 2011.

Gerilowski, K., Krautwurst, S., Kolyer, R., Thompson, D. R., Jonsson, H., Krings, T., Horstjann, M., Leifer, I., Eastwood, M., Green, R. O., Vigil, S., Schuettemeyer, D., Fladeland, M., Burrows, J., and Bovensman, H.: Remote sensing of large-scale methane emission sources with the Methane Airborne MAPper (MAMAP) instrument over Kern River and Kern Front oil fields and validation through airborne in-situ measurements initial results from COMEX, in: AGU Fall Meeting, San Francisco, CA, USA, available at: https://agu.confex.com/agu/fm14/ meetingapp.cgi\#Paper/21807 (last access: 5 June 2015), 2014.

Gerilowski, K., Krings, T., Hartmann, J., Buchwitz, M., Sachs, T., Erzinger, J., Burrows, J. P., and Bovensmann, H.: Atmospheric Remote Sensing Constraints on direct SeaAir Methane Flux from the 22/4b North Sea Massive Blowout Bubble Plume, Marine and Petroleum Geology, doi:10.1016/j.marpetgeo.2015.07.011, online first, 2015.

Google Earth, Inc.: Google Earth Imagery, available at: https:// earth.google.com/ (last access: 5 June 2015), 2015.

Green, R. O.: Spectral calibration requirement for Earth-looking imaging spectrometers in the solar-reflected spectrum, Appl. Optics, 37, 683-690, 1998.

Green, R. O., Carrere, V., and Conel, J. E.: Measurement of atmospheric water vapor using the Airborne Visible/Infrared Imaging Spectrometer, in: Proc. ASPRS Conference on Image Processing, 1989.

Green, R. O., Eastwood, M. L., Sarture, C. M., Chrien, T. G., Aronsson, M., Chippendale, B. J., Faust, J. A., Pavri, B. E., Chovit, C. J., Solis, M., M. Olah, R., Williams, O., and Imaging Spectroscopy and the Airborne Visible/Infrared Imaging Spectrometer (AVIRIS): Imaging spectroscopy and the airborne visible/infrared imaging spectrometer (AVIRIS), Remote Sens. Environ., 65, 227-248, 1998.

Hamlin, L., Green, R. O., Mouroulis, P., Eastwood, M., Wilson, D., Dudik, M., and Paine, C.: Imaging spectrometer science measurements for terrestrial ecology: AVIRIS and new develop- ments, IEEE Aerospace Conference, Big Sky, Montana, USA, 1-7 March, 2011.

Karaska, M. A., Huguenin, R. L., Beacham, J. L., Wang, M.-H., Jensen, J. R., and Kaufmann, R. S.: AVIRIS measurements of chlorophyll, suspended minerals, dissolved organic carbon, and turbidity in the Neuse River, North Carolina, Photogramm. Eng. Rem. S., 70, 125-133, 2004.

Kay, S., Hedley, J. D., and Lavender, S.: Sun glint correction of high and low spatial resolution images of aquatic scenes: a review of methods for visible and near-infrared wavelengths, Remote Sensing, 1, 697-730, 2009.

Keymeulen, D., Aranki, N., Bakhshi, A., Luong, H., Sarture, C., and Dolman, D.: Airborne demonstration of FPGA implementation of Fast Lossless hyperspectral data compression system, in: Adaptive Hardware and Systems (AHS), 2014 NASA/ESA Conference, IEEE, 278-284, 2014.

Krings, T., Gerilowski, K., Buchwitz, M., Reuter, M., Tretner, A., Erzinger, J., Heinze, D., Pflüger, U., Burrows, J. P., and Bovensmann, H.: MAMAP - a new spectrometer system for columnaveraged methane and carbon dioxide observations from aircraft: retrieval algorithm and first inversions for point source emission rates, Atmos. Meas. Tech., 4, 1735-1758, doi:10.5194/amt-41735-2011, 2011.

Krings, T., Gerilowski, K., Buchwitz, M., Hartmann, J., Sachs, T., Erzinger, J., Burrows, J. P., and Bovensmann, H.: Quantification of methane emission rates from coal mine ventilation shafts using airborne remote sensing data, Atmos. Meas. Tech., 6, 151-166, doi:10.5194/amt-6-151-2013, 2013.

Krueger, A., Stremme, W., Harig, R., and Grutter, M.: Volcanic $\mathrm{SO} 2$ and SiF4 visualization using 2-D thermal emission spectroscopy -Part 2: Wind propagation and emission rates, Atmos. Meas. Tech., 6, 47-61, doi:10.5194/amt-6-47-2013, 2013.

Kruse, F., Kim, A., Runyon, S., Carlisle, S. C., Clasen, C., Esterline, C., Jalobeanu, A., Metcalf, J., Basgall, P., Trask, D., and Olsen, R. C.: Multispectral, hyperspectral, and LiDAR remote sensing and geographic information fusion for improved earthquake response, in: SPIE Defense + Security, International Society for Optics and Photonics, Baltimore, Maryland, USA, 9088, 90880K, doi:10.1117/12.2049725, 2014.

Kruse, F. A.: Mapping surface mineralogy using imaging spectrometry, Geomorphology, 137, 41-56, 2012.

Leifer, I., Lehr, W. J., Simecek-Beatty, D., Bradley, E., Clark, R., Dennison, P., Hu, Y., Matheson, S., Jones, C. E., Holt, B., Reif, M., Roberts, D. A., Svejkovsky, J., Swayze, G., and Wozencraft, J.: State of the art satellite and airborne marine oil spill remote sensing: application to the BP Deepwater Horizon oil spill, Remote Sens. Environ., 124, 185-209, 2012.

Leifer, I., Melton, C., Gupta, M., and Leen, B.: Mobile Monitoring of Methane Leakage, Gases and Instrumentation, Gases and Instrumentation International, Wellesley Hills, MA, USA, 2014.

Lübcke, P., Bobrowski, N., Illing, S., Kern, C., Alvarez Nieves, J. M., Vogel, L., Zielcke, J., Delgado Granados, H., and Platt, U.: On the absolute calibration of $\mathrm{SO}_{2}$ cameras, Atmos. Meas. Tech., 6, 677-696, doi:10.5194/amt-6-677-2013, 2013.

Mandl, D., Sohlberg, R., Justice, C., Ungar, S., Ames, T., Frye, S., Chien, S., Tran, D., Cappelaere, P., Sullivan, D., and Ambrosia, V.: A space-based sensor web for disaster management, in: Geoscience and Remote Sensing Symposium, IGARSS 2008, IEEE International, vol. 5, V-294, 2008. 
Manolakis, D., Lockwood, R., Cooley, T., and Jacobson, J.: Hyperspectral detection algorithms: use covariances or subspaces?, in: SPIE Optical Engineering Applications, International Society for Optics and Photonics, Imaging Spectrometry XIV, San Diego, USA, 74570Q, 2009.

Manolakis, D., Truslow, E., Pieper, M., Cooley, T., and Brueggeman, M.: Detection algorithms in hyperspectral imaging systems: an overview of practical algorithms, IEEE Signal Proc. Mag., 31, 24-33, 2014.

Matricardi, M.: RTIASI-4, a new version of the ECMWF fast radiative transfer model for the infrared atmospheric sounding interferometer, European Centre for Medium-Range Weather Forecasts (ECMWF), Reading, UK, ECMWF Technical Memorandum, 425, 1-63, 2003.

Müller, J.-F. and Brasseur, G.: IMAGES: A three-dimensional chemical transport model of the global troposphere, J. Geophys. Res.-Atmos., 100, 16445-16490, 1995.

Popp, C., Brunner, D., Damm, A., Van Roozendael, M., Fayt, C., and Buchmann, B.: High-resolution $\mathrm{NO}_{2}$ remote sensing from the Airborne Prism EXperiment (APEX) imaging spectrometer, Atmos. Meas. Tech., 5, 2211-2225, doi:10.5194/amt-5-22112012, 2012.

Reuter, R., Wang, H., Willkomm, R., Loquay, K., Hengstermann, T., and Braun, A.: A laser fluorosensor for maritime surveillance: measurement of oil spills, EARSeL Adv. Remote Sens., 3, 152169, 1995.

Roberts, D. A., Bradley, E. S., Cheung, R., Leifer, I., Dennison, P. E., and Margolis, J. S.: Mapping methane emissions from a marine geological seep source using imaging spectrometry, Remote Sens. Environ., 114, 592-606, 2010.

Rolph, G.: Real-time Environmental Applications and Display sYstem (READY) Website, NOAA Air Resources Laboratory, Silver Spring, MD, USA, available at: http://www.arl.noaa.gov/ready/ hysplit4.html (last access: 22 September 2015), 2003.

Sandsten, J., Weibring, P., Edner, H., and Svanberg, S.: Real-time gas-correlation imaging employing thermal background radiation, Opt. Express, 6, 92-103, 2000.

Schaum, A. and Stocker, A.: Long-interval chronochrome target detection, in: Proc. 1997 International Symposium on Spectral Sensing Research, 1760-1770, 1998.

Sorenson, C. E., Forgione, J., and Barnes, C.: The NASA Airborne Science Data And Telemetry System (NASDAT), AGU Fall Meeting Abstracts, 1, 1283, 2011.

Stein, D. W., Beaven, S. G., Hoff, L. E., Winter, E. M., Schaum, A. P., and Stocker, A. D.: Anomaly detection from hyperspectral imagery, IEEE Signal Proc. Mag., 19, 58-69, 2002.

Stremme, W., Krueger, A., Harig, R., and Grutter, M.: Volcanic SO2 and SiF4 visualization using 2-D thermal emission spectroscopy -Part 1: Slant-columns and their ratios, Atmos. Meas. Tech., 5, 275-288, doi:10.5194/amt-5-275-2012, 2012.

Theiler, J., Foy, B. R., and Fraser, A. M.: Characterizing nonGaussian clutter and detecting weak gaseous plumes in hyperspectral imagery, in: Defense and Security, International Society for Optics and Photonics, Orlando, Florida, USA, 182-193, 2005.
Thompson, D. R., Bornstein, B. J., Chien, S. A., Schaffer, S., Tran, D., Bue, B. D., Castaño, R., Gleeson, D. F., and Noell, A.: Autonomous spectral discovery and mapping onboard the EO-1 spacecraft, IEEE T. Geosci. Remote, 51, 3567-3579, $2013 \mathrm{a}$.

Thompson, D. R., de la Torre Juárez, M., Barker, C. M., Holeman, J., Lundeen, S., Mulligan, S., Painter, T. H., Podest, E., Seidel, F. C., and Ustinov, E.: Airborne imaging spectroscopy to monitor urban mosquito microhabitats, Remote Sens. Environ., 137, 226-233, 2013b.

Thompson, D. R., Green, R. O., Keymeulen, D., Lundeen, S. K., Mouradi, Y., Nunes, D. C., Castano, R., and Chien, S. A.: Rapid spectral cloud screening onboard aircraft and spacecraft, IEEE Trans. Geosci. Remote Sens., 52, 6779-6792, 2014.

Thorpe, A. K., Roberts, D. A., Bradley, E. S., Funk, C. C., Dennison, P. E., and Leifer, I.: High resolution mapping of methane emissions from marine and terrestrial sources using a ClusterTuned Matched Filter technique and imaging spectrometry, Remote Sens. Environ., 134, 305-318, 2013.

Thorpe, A. K., Frankenberg, C., and Roberts, D. A.: Retrieval techniques for airborne imaging of methane concentrations using high spatial and moderate spectral resolution: application to AVIRIS, Atmos. Meas. Tech., 7, 491-506, doi:10.5194/amt-7491-2014, 2014.

Thorpe, A. K., Frankenberg, C., Aubrey, A., Roberts, D., Nottrott, A., Rahn, T., Sauer, J., Dubey, M., Costigan, K., Arata, C., Steffke, A. M., Hills, S., Haselwimmer, C., Charlesworth, D., Funk, C., Green, R., Lundeen, S., Boardman, J., Eastwood, M., Sarture, C., Nolte, S., Mccubbin, I., Thompson, D., and McFadden, J.: Measuring methane concentrations from a controlled release experiment using the next generation Airborne Visible/Infrared Imaging Spectrometer (AVIRIS-NG), Remote Sens. Environ., submitted, 2015.

Ustin, S. L., DiPietro, D., Olmstead, K., Underwood, E., and Scheer, G.: Hyperspectral remote sensing for invasive species detection and mapping, in: Geoscience and Remote Sensing Symposium, 2002, IGARSS'02, 3, 1658-1660, 2002.

Ustin, S. L., Roberts, D. A., Gamon, J. A., Asner, G. P., and Green, R. O.: Using imaging spectroscopy to study ecosystem processes and properties, BioScience, 54, 523-534, 2004.

Van Gilst, D. P. and Sorenson, C. E.: Collection, storage and realtime transmission of housekeeping and instrument data aboard manned NASA airborne science platforms, AGU Fall Meeting Abstracts, 1, 1588, 2011.

Vogel, L., Galle, B., Kern, C., Delgado Granados, H., Conde, V., Norman, P., Arellano, S., Landgren, O., Lübcke, P., Alvarez Nieves, J. M., Cárdenas Gonzáles, L., and Platt, U.: Early inflight detection of $\mathrm{SO}_{2}$ via Differential Optical Absorption Spectroscopy: a feasible aviation safety measure to prevent potential encounters with volcanic plumes, Atmos. Meas. Tech., 4, 17851804, doi:10.5194/amt-4-1785-2011, 2011. 